\title{
Papyri to the rescue: reconstructing Hellenistic male-female couple' relationships through papyrological documentation
}

The relationships of ordinary male-female couples in Antiquity remain a field of research still little explored, especially regarding the study of feelings, emotions, real-life experiences, and couple dynamics through everyday life. Thus, it is essential to look into this theme, both in the Greek and Roman worlds, in a diachronic and synchronic perspective; this is the purpose of a Swiss National Science Foundation (SNF) project at the University of Lausanne, entitled "Couple relationships in Antiquity". My $\mathrm{PhD}$ thesis, as part of this project, intends to explore couple relationships during the Hellenistic period, in Greece, Asia Minor, and Ptolemaic Egypt, through literary, epigraphic, and papyrological documentation.

In this context, Greek papyri provide notable elements, that can complement and counteract the data issued from literary sources and inscriptions whose one of the biases is to present an idealized or incomplete vision of couples' relationships; nevertheless, we must keep in mind that papyri suffer from their own specific biases.My aim in this paper is to show how possible it is to integrate different types of papyri - letters, marriage contracts, wills, complaints, etc - as part of a study on couples' real-life experience, while identifying some of the key methodological aspects necessary for this type of analysis, by presenting excerpts from several documents. Furthermore, the addition of an adequate methodological canvas allows going beyond the cultural and/or typological filters and biases inherent to this type of documentation, and its inclusion in the global corpus of my thesis, in which most documents are from the 'classical' Greek world. 